\title{
Payments for environmental services (PES): contribution to Indigenous livelihoods
}

\author{
R. Greiner \\ Charles Darwin University, Australia
}

\begin{abstract}
Indigenous people living in Australia's tropical savanna landscapes are increasingly looking towards income opportunities from the provision of environmental services as an avenue for economic development and improvement in socio-economic conditions. A number of programs, which can be classified as payments for environmental services, support the existence and operation of Indigenous land and sea management groups, also referred to as Indigenous ranger groups. Rangers undertake a portfolio of activities, including feral animal and weed control, biodiversity monitoring and protection, fire management, and biosecurity and border protection assignments. This paper reviews the extent to which current activities contribute to Indigenous livelihoods and discusses their likely growth potential and livelihood contribution in the future.

The terms 'Indigenous' and 'Traditional Owners' are capitalised in this paper as they refer to descendants of the original inhabitants of Australia.

Keywords: payments for environmental services, livelihoods, Indigenous people, assessment, Australia.
\end{abstract}

\section{Introduction}

Australia's tropical savannas encompass approximately one quarter of the continent (around 1.9 million $\mathrm{km}^{2}$ ) and span northern Queensland (Q1d), the Northern Territory (NT) and northern Western Australia (WA). The population density of the tropical savannas is low $\left(<0.2\right.$ persons per $\left.\mathrm{km}^{2}\right)$, with fewer than 500,000 persons living in the region [1,2]. A large proportion of the resident population is Indigenous. Indigenous people are those who self-identify as being of Aboriginal or Torres Strait Islander descent and are accepted by the 


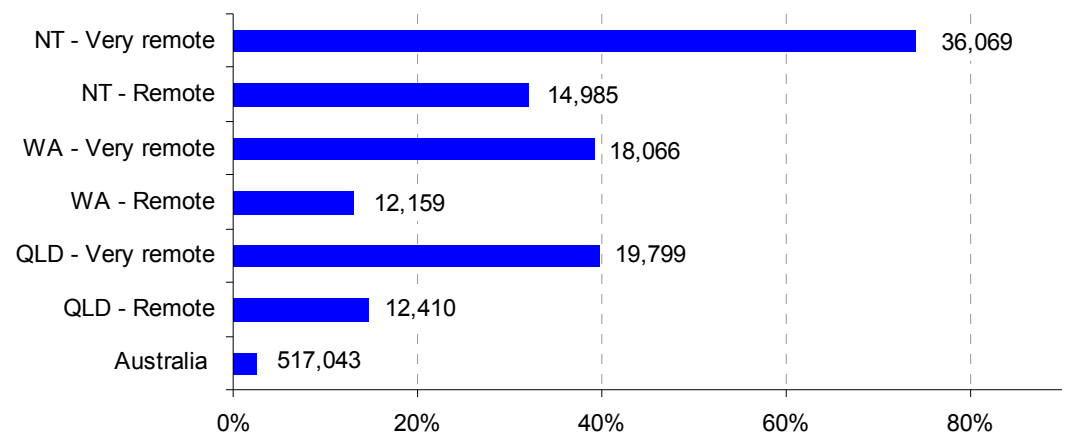

Indigenous population, percentage of residential population (\%) and number of persons

Figure 1: Indigenous population in 'remote' and 'very remote' regions (compiled from [3]).

community as such. Indigenous people account for up to $75 \%$ of the residential population in some of the 'very remote' areas of the tropical savannas [3], fig 1.

'Remote' and 'very remote' areas of the NT and Qld are amongst the most socio-economically disadvantaged areas of Australia [5]. Indigenous populations in particular tend to be characterised by low workforce participation and high unemployment [6]. The employment profile of the 27,950 Indigenous persons who were employed across northern Australia at the date of National Census of Population and Housing in 2006 [4] shows high levels of employment particularly in public service and health-related industries, fig.2. The third largest category is 'unspecified', which may relate to people participating in the Community Development Employment Projects (CDEP) scheme, which in 2006 was still generally operational. The CDEP scheme enabled members of Indigenous communities, particularly in remote and very remote areas, to exchange unemployment benefits for opportunities to undertake paid work and training in activities managed by a local Indigenous community organisation. The 'unspecified' category could possibly also relate to employment in the natural resource management sector, which does not fit well with the industry profile adopted for census data collection.

A major factor is the virtual absence of the commercial sector, other than the mines operating in some places. Being employed in natural resource management, working on country and being paid for providing environmental services is thus an appealing concept. It deserves major consideration in the discussion about future development trajectories for tropical savannas [2], particularly since these landscapes produce among the highest per-hectare ecosystem values in Australia [7]. The abundance of natural capital - in terms of size and quality - provides market opportunities but also poses a number of challenges [8]. 


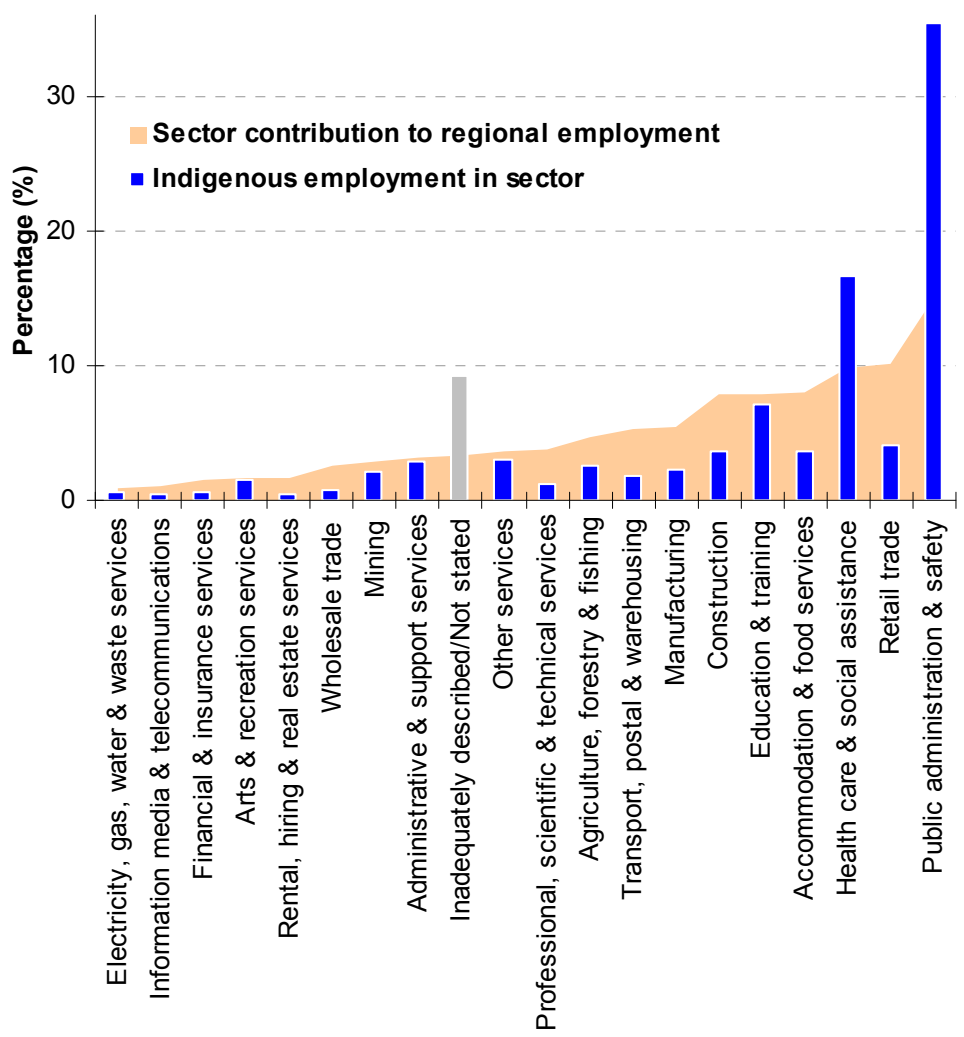

Figure 2: $\quad$ Employment in northern Australia, by industry (compiled from [4] for Kimberley, NT, North Qld and Far North Qld).

Following some necessary clarification of terminology in section 2, the paper goes on to describe Indigenous land and sea management initiatives and illustrates existing PES schemes of relevance (section 3). It concludes with an integrated assessment of the likely livelihood benefits from such schemes for Indigenous Australians in northern Australia (section 4).

\section{Payments for environmental services}

Environmental services are conceptually distinct from ecosystem services. The notion of "ecosystem services" is outcome-based and focused on the wellbeing benefits provided to society from natural capital. In contrast, the notion of "environmental services" is input-based and focuses on the efforts undertaken by actors to generate environmental improvements and improved natural capital [9], fig.3. 


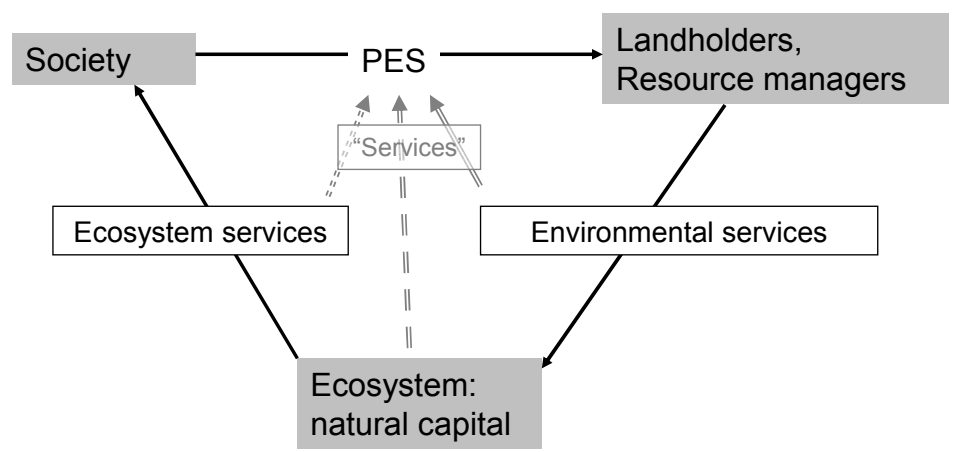

Figure 3: $\quad$ PES in the context of environmental and ecosystem services [8].

In the literature, the acronym PES is used to mean either payments for environmental services or payments for ecosystem services, with little distinction between the two. A review of a dozen PES schemes operating in Australia, Europe and north and south America showed that in fact most PES schemes pay for the provision of environmental services [8]. The definition adopted here is, therefore, that PES is a price mechanism for translating non-market values into financial incentives for actors (i.e. people and businesses) who provide environmental services $[9,10]$.

There are five principal elements to PES [11]:

1. PES are based on a voluntary, negotiated contract between suppliers of environmental services and a buyer. Suppliers have a choice of entering into contractual arrangements but if they do they must provide the environmental service.

2. The service must be well-defined. If it is not directly measurable-as is the case with most environmental outcomes - surrogate measures are required that are directly linked to the provision of the service.

3. There needs to be at least one buyer. The buyer can be a government, acting on behalf of a community, or a private entity or non-government organisation. There are often brokers or intermediaries involved in functioning environmental or ecosystem services markets.

4. There also needs to be at least one supplier/provider. In most cases, there will be many providers.

5. Payments are made conditional on the supplier meeting the service delivery specifications to ensure the effectiveness of the scheme.

Supply of environmental services is principally driven by the price received for environmental services, opportunity costs, risk and the institutional framework, fig.4. If, for example, statutory requirements demand a high level of environmental service provision as part of an actor's environmental duty of care, the scope for PES is reduced. Demand is principally driven by the utility that users derive from ecosystem services, the number of users, and their willingness to pay. Whether a market will emerge is further influenced by the clarity of trading rules and the level of transaction costs, which can be significantly 


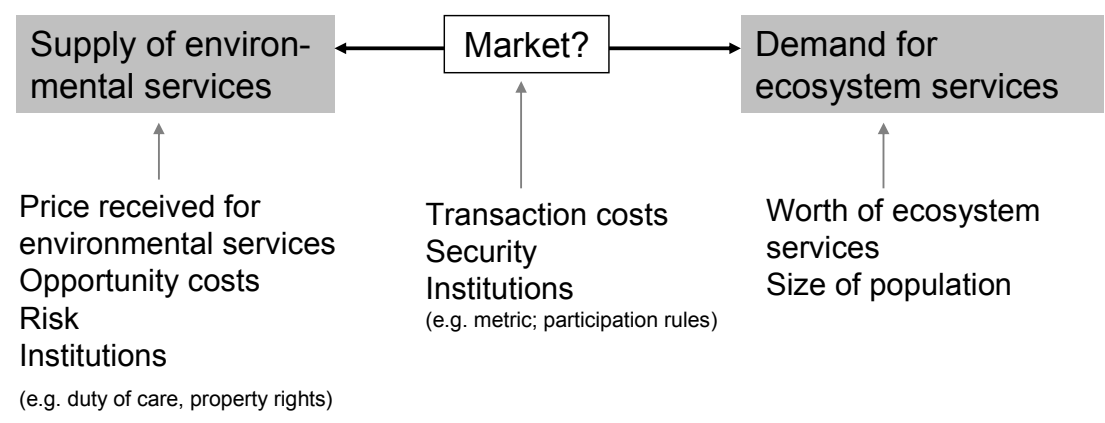

Figure 4: Determinants of markets for environmental services [8].

reduced in monopsony (single buyer) situations [12]. Because of the inherent complexity and characteristics of the natural and social systems that they interact with, PES might not always be the most effective policy tool for the provision of ecosystem services [12].

\section{PES involving Indigenous people in northern Australia}

\subsection{Context}

In 2000, the Council of Australian Governments (COAG-i.e. the Australian Government and the seven state and territory governments) agreed to endorse a National Action Plan to address the natural resource issues of salinity and water quality [13]. In doing so, it effectively instituted a nation-wide PES scheme with the intention to enable and motivate regional communities to use coordinated and targeted action to address a number of environmental degradation problems through landscape-scale change. Regional natural resource management (NRM) groups were set up across the country to act as coordinators and brokers between the government - as monopsony buyer - and landholders as the providers of environmental services. Importantly, following the recognition of Native Title in 1993, Traditional Owners were recognised as key stakeholders in NRM and a formal avenue established for their engagement in the governance, management and on-ground dimensions of regional NRM. The stated objective of this engagement is to capture the significant economic and socio-cultural benefits associated with NRM, specifically in areas where there are few commercial avenues for improving socioeconomic well-being [14].

Indigenous people refer to NRM as 'caring for country'. Caring for country is an inclusive concept in that 'country' includes both land and sea country and 'caring' relates to country as well as people. Over the past decade, Indigenous engagement in NRM has grown through increasing involvement of Traditional Owners (i) organisationally, through the establishment of Indigenous land management facilitator positions within NRM groups and the development of Indigenous land and sea management/Indigenous ranger groups, and (ii) operationally, through an increasing suite of on-ground programs, which now 
operate within and outside the formal NRM domain. In northern Australia in particular, Indigenous engagement in caring for country has been strong due to the comparatively high levels of continuity of connection of Traditional Owners with their country since European settlement.

\subsection{Indigenous land and sea management}

Indigenous engagement in caring for country is organised differently in different states and territories. In the NT, where Aboriginal people own over $50 \%$ of the land mass and $84 \%$ of the coastline, some 46 Indigenous land and sea management groups with around 500 members were operating in 2007 [15]. The groups are principally supported in their operations by the Indigenous land councils while the 2003-founded North Australian Indigenous Land \& Sea Management Alliance (NAILSMA [16]), which also operates in northern Qld, and northern WA, plays an important advocacy role. In Qld, Indigenous caring for country activities tend to align with regional NRM groups, which-under the auspices of the Statewide Indigenous Network Coordination Project-employ Indigenous facilitators and fund traditional owner involvement in caring for country activities [17]. Some traditional owner groups are self-organised as Indigenous land and sea management or ranger groups, while others operate under state government auspices (e.g. Wild river rangers [18]).

The portfolio of caring for country activities include, e.g., feral animal and weed control, biodiversity monitoring, threatened species protection, fire management and coastal rehabilitation. Some groups conduct surveillance and quarantine related activities. An important aspect of Indigenous land and sea management is the continued growth of social and human capital through training and education programs, policy and planning, advocacy, and community development projects.

Indigenous land and sea management is principally funded by government. Two types of funding exist, what one might call 'core funding' and 'projectbased funding'. Core funding comes, inter alia, from wage support (such as CDEP), Indigenous infrastructure and activity funding, Indigenous environmental and cultural heritage programs, resources for training and resources for business and industry development [15]. While accountability criteria apply to core funding, it is project-based (or grant) funding that can be interpreted as PES. The following examples serve to illustrate PES-style projects for Indigenous caring for country activities that operate at present in the tropical savannas.

\subsection{Removal of marine debris from remote beaches}

Circular currents in the waters off northern Australia mean that marine debris (i.e. any manufactured or solid processed material that enters the marine environment from any source [19]) which enters the Gulf of Carpentaria, remains trapped in those currents and accumulates. Even after being dumped on beaches, marine debris often gets re-suspended during high-wind events [20]. Discarded 
fishing nets, so-called 'ghost nets', pose a key concern as they 'continue to fish' and kill marine wildlife while they remain suspended in the sea [21].

The Ghost Nets Programme commenced in 2004 with the objective to remove discarded fishing gear and other marine debris from coastline around the Gulf of Carpentaria to support biodiversity conservation, and to release trapped animals.

The program is coordinated through the Northern Gulf Resource Management Group, a regional NRM group. Coastal clean-up services are provided by an alliance of Indigenous communities surrounding the Gulf of Carpentaria who refer to themselves 'saltwater people'. Work is carried out by members of the Indigenous rangers groups of participating communities-currently 18 ranger groups across Qld and the NT. In the first 4 $\frac{1}{2}$ years of the program's existence, Indigenous rangers removed approximately $90 \mathrm{~km}$ of ghost nets [22]. The NRM group submitted a bid to the Australian Government's 2009 Caring for Our Country program and secured funding of approximately AU\$ 1 million per year for an additional three years for the program.

The Ghostnet Programme illustrates a number of issues associated with government-related funding for PES schemes: (i) Continuity of grants-based schemes is uncertain and difficult to achieve given election cycles, changes in government priorities and competitive allocation of funds. (ii) Funding is generally at a level that does not provide for employment of Indigenous rangers for a singular environmental service: In comparative terms, funding for the Ghost Nets Programme is substantial. However, even if administrative and management costs are small, participating land and sea management groups receive on average less than AU\$ 50,000 per annum to cover wages and operating expenses.

\subsection{Controlled savanna burning to reduce the level of fire-related greenhouse gas emissions}

Wild fires play an important role in tropical savannas. Fire has a major influence in shaping the vegetation, with frequent dry season fires limiting tree recruitment and keeping the canopy open [23]. However, fires consume vegetation and, in doing so, produce $\mathrm{CO}_{2}$ and other greenhouse gases. While fires are a natural phenomenon, the timing and intensity of fire, and consequently its various ecological impacts, can be significantly influenced by fire management activities. In savanna landscapes, fire management based on traditional Indigenous knowledge and fire management practices, and supported by modern technology, can substantially reduce greenhouse gas emissions and generate biodiversity benefits in comparison to an 'unmanaged' situation, such as that which arose post European settlement [24].

The West Arnhem Land Fire Abatement (WALFA) Project harnesses these relationships $[24,25]$. The project is a contractual 17-year partnership between the Aboriginal owners and five affiliated Indigenous ranger groups, Darwin Liquefied Natural Gas (LNG), the Northern Territory Government and the Northern Land Council as broker. Through this partnership, Indigenous ranger groups are implementing strategic fire management across $28,000 \mathrm{~km}^{2}$ of 
Western Arnhem Land to offset greenhouse gas emissions from the liquefied natural gas plant in the city of Darwin. Darwin LNG pays the Indigenous land and sea management groups around AU\$ 1 million per year to provide this specialised fire management service with an annual sequestration target of $100,000 \mathrm{t} \mathrm{CO}_{2}$-equivalent $\left(\mathrm{CO}_{2} \mathrm{e}\right)$ relative to a 10-year (1995-2004) baseline of the region's fire-derived greenhouse gas emissions [26]. Between 2005 and 2008 , the project has achieved a measurable reduction in destructive wild fires and an estimated average annual reduction in release of greenhouse gases from the contracted area of $122,000 \mathrm{t} \mathrm{CO}_{2} \mathrm{e}$ per annum [24].

The outcomes achieved by the West Arnhem Fire project, both procedural and operational, have potential application across fire-prone tropical Australia as well as fire-prone tropical regions elsewhere [25].

The WALFA project demonstrates the potential scope for commercially funded large-scale PES schemes. Long-term contracts between companies and services providers can offer high levels of security and continuity for both parties. However, the existence of such schemes depends on government providing policy settings which underpin markets for environmental goods such as $\mathrm{CO}_{2} \mathrm{e}$. Legislative frameworks that set pollution caps and accounting and trading rules fundamentally determine the existence of a market, potential participants, transaction costs and per-unit prices. At an approximate level of payment of $\$ 10 /$ tonne $\mathrm{CO}_{2} \mathrm{e}$ or approximately $\$ 35-46 / \mathrm{km}^{2}$, even commercial PES schemes of a WALFA nature are unlikely to sustain land and sea management groups in their own right either financially or operationally, as burning activities are seasonally limited.

\subsection{Provision of surveillance and quarantine services}

Australia's northern coastline is vast and sparsely populated, making it vulnerable to undetected foreign vessels that bypass the usual quarantine checks at Australian borders. There is also a risk that pests could enter Northern Australia from neighbouring countries, using migrating birds, human activities or wind currents as carriers [27].

The Northern Australia Quarantine Strategy was established by the Australian Quarantine and Inspection Service (AQIS) in 1989 and conducts surveys along Australia's northern coastline and in neighbouring countries for early signs of new pests or disease. AQIS engages Indigenous land and sea management groups (20 groups in the NT, 12 in WA, 8-10 in Qld) on a fee-for-service basis to support surveillance and quarantine efforts. Indigenous rangers harvest feral pigs, inspect them for the presence of serious exotic diseases like foot and mouth disease, and take blood samples for further analysis [28].

Such fee-for-service arrangements offer continuity of funding since the need for services is ongoing and there are no alternative service providers. Given skills required to undertake tasks, this may provide 'permanent' jobs for some members of Indigenous land and sea management units and offer a stable contribution to the funding of ranger groups. 


\section{Assessment of PES: contribution to Indigenous livelihoods}

PES schemes typically operate where natural assets are scarce and/or under immediate threat. The need for relative scarcity poses a challenge for the savannas of northern Australia, where natural capital is relatively abundant and population is sparse: those who provide environmental services need to largely cater to the demand for ecosystem services from people elsewhere. Not everybody who provides an environmental service can expect payment "since services that are neither highly valuable and/or not threatened are unlikely to find buyers" $[11$, p.5]. However, in the abundance also lies a market opportunity in that buyers aiming to protect existing but locally and/or globally threatened services may want to anticipate emerging threats and future cost rises - similar to the concept of ecological insurance against uncertain futures. If they delay purchasing services until after changes have occurred, stocks of natural capital will be low and ecosystem services more scarce (some may already have been irreversibly lost) and the cost of delivering environmental services will be more expensive [8]. Also, in the case of greenhouse gases, abatement costs in savanna landscapes may be lower than elsewhere.

In the tropical savannas context, matters of size, low opportunity costs from forgone production, the pristine state of many areas, and uniqueness, enhance the marketability of existing ecosystem services. There is an Indigenous labour force scattered throughout the landscape in settlements and outstations, where employment and commercial opportunities are limited. Over the past decade, Indigenous land and sea management has successfully harnessed this combination and grown into a successful avenue for employment and economic development that builds on Indigenous people's skills, interests, location and land ownership.

Comparatively speaking, Indigenous NRM is not a large industry, with approximately 500 workers employed in the NT. At an individual level, however, it can be argued that every one of these jobs makes a difference to an Indigenous person and, possibly, a family. In addition to employment and income, these jobs generate pride, recognition, skills, work ethic and other social values which may be able to help address some causes of the socio-economic disadvantage faced by 'remote' and 'very remote' Indigenous communities. It may provide a foundation for other initiatives and more employment in other industries. As the population of Indigenous communities, particularly in remote areas, grows rapidly [2], the relative contribution that caring for country can provide to community livelihoods is likely to diminish over time.

There are limits to the growth of this new industry. Caring for country is essentially a public sector industry with government-albeit through various agencies and possibly through different levels of government-as the single or dominant purchaser of services. As such both 'core' funding and grant funding are subject to government persuasion, election cycles, and changing priorities and policy manifestations. While there are multiple sources of grant funding, transaction costs for ranger groups associated with competitive funds are high and the ability of groups to demonstrate their capacity to deliver is fundamental 
for their viability. Ongoing investment in ranger education and skills development are critical, yet this cannot be funded by PES schemes. Consequently, groups will continue to rely on 'core' government funding to be operational and competitive.

The WALFA project has shown that commercial PES arrangements for environmental services provided on Indigenous lands by Indigenous rangers are feasible. However, the opportunity for expansion of such arrangements - in particular as they relate to greenhouse gas abatement-is uncertain. The WALFA project can be considered a philanthropic project, since there are currently no legal requirements for greenhouse gas emitters in Australia to offset their emissions. Large-scale fire management across tropical savannas under commercial arrangements will only eventuate if there is a market. A market only operates if government policy has set the necessary institutional foundations. If the Australian Government succeeds in introducing a greenhouse gases cap-andtrade system, the future for such schemes across the tropical savannas is bright.

\section{Acknowledgements}

I would like to thank Heather Aslin and Julie Crough for helpful comments on an earlier draft of this paper.

\section{References}

[1] Woinarski, J., Mackey, B., Nix, H., and Traill, B. 2007. The nature of northern Australia - Natural values, ecological processes and future prospects. ANU Press: Canberra

[2] Garnett, S., Woinarski, J., Gerritsen, R., and Duff, G. 2008. Future options for North Australia. Charles Darwin University Press: Darwin.

[3] Australian Bureau of Statistics. 2008. Experimental Estimates of Aboriginal and Torres Strait Islander Australians, Jun 2006. Cat. No. 3238055001DO004_200606. Commonwealth of Australia: Canberra.

[4] Australian Bureau of Statistics. 2007. Industry of Employment by Indigenous Status. Cat. No. 2068.0 - 2006 Census Tables. Commonwealth of Australia: Canberra.

[5] Australian Bureau of Statistics. 2008. Socio-Economic Indexes for Areas (SEIFA). Cat. No. 2033.0.55.001. Commonwealth of Australia: Canberra.

[6] Australian Bureau of Statistics. 2008. Australian Social Trends 2008. Cat. No. 4102.0. Commonwealth of Australia: Canberra.

[7] Costanza, R., d'Arge, R., de Groot, R., Farber, S., Grasso, M., Hannon, B., Limburg, K., Naeem, S., O’Neill, R.V., Paruelo, J., Raskin, R.G., Sutton, P. and van den Belt, M. 1997. The value of the world's ecosystem services and natural capital. Nature 387, 253-260.

[8] Greiner, R., Gordon, I. and Cocklin, C. 2009. Ecosystem services from tropical savannas: economic opportunities through payments for environmental services. The Rangeland Journal 31, 51-59. 
[9] Fisher, B., Turner, R.K., and Morling, P. 2008. Defining and classifying ecosystem services for decision making. Ecological Economics 68, 643653.

[10] Engel, S., Paiola, S., and Wunder, S. 2008. Designing payments for environmental services in theory and practice: An overview of the issues. Ecological Economics 65, 663-674.

[11] Wunder, S. 2005. Payments for environmental services: some nuts and bolts. Occasional Paper No 42. Center for International Forestry Research: Jakarta, Indonesia.

[12] Kemkes, R.J., Farley, J., and Koliba, C.J. 2009. Determining when payments are an effective policy approach to ecosystem service provision. Ecological Economics doi:10.1016/j.ecolecon.2009.11.032

[13] Keogh, K., Chant, D., and Frazer, B. 2006. Review of arrangements for regional delivery of natural resource management programmes. Ministerial Reference Group for Future NRM Programme Delivery: Canberra.

[14] Altman, J., and Whitehead, P. 2003. Caring for country and sustainable Indigenous development: Opportunities, constraints and innovation. CAEPR Working Paper No. 20/2003. Centre for Aboriginal Economic Policy Research, Australian National University: Canberra.

[15] Putnis, A, Josif, P., and Woodward, E. 2007. Healthy Country, Healthy People: Supporting Indigenous Engagement in the Sustainable Management of Northern Territory Land and Seas: A Strategic Framework. CSIRO: Darwin.

[16] NAILSMA 2009. About NAILSMA. Online at: http://www.nailsma. org.au/about_nailsma/index.html. Accessed: 01/01/2010.

[17] Qld Regional Group Collective. 2009. Indigenous land and sea management in Queensland. Online at: http://www.rgc.org.au/. Accessed: 03/01/2010.

[18] Qld government. 2009. Wild river rangers. Online at: http://www.regionalnrm.qld.gov.au/policies_plans_legislation/ policies_strategies/wild_river_rangers.html. Accessed: 03/01/2010.

[19] Coe, J and Roger D. (Eds.). 1997. Marine Debris Sources, Impacts and Solutions. Springer-Verlag, New York

[20] Carpentaria Ghost Nets Programme. 2009. About the program. Online at: http://www.Ghost Nets.com.au/about.html. Accessed: 01.01.2010.

[21] Anon. 2006. Marine debris in Northern Australia: A short history of work on the problem. Online at: http://www.Ghost Nets.com.au/data/History marine_debris_northernAustralia.pdf. Accessed: 01/01/2010.

[22] Carpentaria Ghost Nets Programme. 2009. Survey results. Online at: http://www.Ghost Nets.com.au/data. Accessed: 01.01.2010.

[23] Dyer, R., Jacklyn, P., Partridge, I., Russell-Smith, J., and Williams, R. 2001. Savanna Burning: understanding and using fire in northern Australia. Tropical Savannas CRC: Darwin.

[24] Russell-Smith, J., Whitehead, P. and Cooke, P. (Eds.) 2009. Culture, Ecology and Fire Management in North Australian Savannas: Rekindling the Wurrk Tradition. CSIRO Publishing: Collingwood. 
[25] TS-CRC. 2009. The West Arnhem Land Fire Abatement Project (WALFA). Online at: http://www.savanna.org.au/all/walfa.html Accessed $15 / 12 / 09$.

[26] Whitehead, P., Purdon, Pl, Cooke, P., Russell-Smith, J., and Sutton, S. 2009. The West Arnhem Land Fire Abatement (WALFA) project: the institutional environment and its implications. P.298-312, in, RussellSmith, J., Whitehead, P. and Cooke, P. (Eds.) 2009. Culture, Ecology and Fire Management in North Australian Savannas: Rekindling the Wurrk Tradition. CSIRO Publishing: Collingwood.

[27] AQIS. 2009. Northern Australia Quarantine Strategy (NAQS). Online at: http://www.daff.gov.au/aqis/quarantine/naqs. Australian Government Department of Agriculture, Fisheries and Forestry: Canberra. Accessed: $01 / 01 / 2010$.

[28] Tropical Savannas CRC. 2009. Biosecurity: keeping out unwelcome visitors. Online at: http://www.savanna.org.au/all/biosecurity.html. Accessed: 03/01/2010. 